\title{
Cytosolic Prostaglandin E Synthase Is Involved in c-Fos Expression in Rat Fibroblastic 3Y1 Cells
}

\author{
Yoshihito Nakatani,* Yuki Miyazaki, and Shuntaro Hara \\ Division of Health Chemistry, Department of Healthcare and Regulatory Sciences, School of Pharmacy, Showa \\ University; 1-5-8 Hatanodai, Shinagawa-ku, Tokyo 142-8555, Japan. \\ Received June 27, 2017; accepted August 29, 2017
}

\begin{abstract}
Cytosolic prostaglandin (PG) E synthase (cPGES/p23) plays a role in the biosynthesis of PGE $_{2}$ and in the molecular chaperone machinery. Studies of knockout mice lacking cPGES/p23 have demonstrated that cPGES/p23 is essential in fetal mouse development. A cDNA microarray analysis revealed that a lack of cPGES/p23 decreases the expression of some immediate early genes, such as c-fos and activating transcription factor 3 (ATF3). Here we report the involvement of cPGES/p23 in c-Fos expression. A stable knockdown of cPGES/p23 in cultured fibroblasts not only reduced serum-induced c-Fos expression, but also decreased the phosphorylation of extracellular signal regulated kinase (ERK). These results suggest that cPGES/p23 is involved in the activation of ERK to promote c-Fos expression.
\end{abstract}

Key words c-Fos; cytosolic prostaglandin E synthase; extracellular signal regulated kinase; prostaglandin $\mathrm{E}_{2}$

Prostaglandin $\mathrm{E}_{2}\left(\mathrm{PGE}_{2}\right)$ is produced by a variety of tissues and cells, and has a wide variety of biological activities. The biosynthesis of $\mathrm{PGE}_{2}$ is regulated by three sequential steps catalyzed by phospholipase $\mathrm{A}_{2}\left(\mathrm{PLA}_{2}\right)$, cyclooxygenase and PGE synthase. ${ }^{1-3)}$ Cytosolic prostaglandin $\mathrm{E}$ synthase (cPGES), a member of the PGE synthases, isomerizes $\mathrm{PGH}_{2}$ to $\mathrm{PGE}_{2}$, and is constitutively expressed in various cells and tissues. ${ }^{4)}$ This enzyme can be coupled with cyclooxygenase (COX)-1 to promote immediate $\mathrm{PGE}_{2}$ production. The cochaperone $\mathrm{p} 23$, which is associated with heat-shock protein 90 (Hsp90), ${ }^{5}$ is identical to cPGES. ${ }^{4)}$ We have previously shown that Hsp90 regulates both $\mathrm{cPGES} / \mathrm{p} 23$ and its client protein kinase CK2. ${ }^{6,7)}$ A cPGES/p23 deficiency in mice is perinatally lethal and embryos homozygous for cPGES/p23-null exhibit abnormal morphology of the skin and lungs. Moreover, the $\mathrm{PGE}_{2}$ content of the lungs of cPGES/p23-deficient embryos is lower than that of the lungs of wild-type embryos. ${ }^{8)}$ These results indicate that $\mathrm{cPGES} / \mathrm{p} 23$-derived $\mathrm{PGE}_{2}$ is involved in the normal development of the mouse embryonic lung. Furthermore, we have reported that embryonic fibroblasts deficient in cPGES/p23 exhibit decreased expression compared with those of wild-type fibroblasts of the $\mathrm{PGE}_{2}$-degrading enzyme, 15-hydroxyprostaglandin dehydrogenase (15-PGDH), which catalyzes the inactivating oxidation of the $\mathrm{PGE}_{2} 15-\mathrm{OH}$ to a 15 -keto group. ${ }^{9)}$ In the present paper, we report that a microarray analysis of lungs from cPGES/p23-deficient mice revealed a marked reduction in the expression of immediate early genes, particularly c-fos compared with those of the wild-type mice. In addition, rat fibroblastic 3Y1 cells harboring cPGES/p23 small interfering RNA (siRNA) showed a decrease in serum-induced c-Fos expression compared with mock-transfected cells. These results suggest that cPGES/p23 is involved in c-Fos expression.

c-Fos, a member of the immediate early gene family, can dimerize with c-Jun to form activator protein 1 (AP-1), which regulates key cellular processes, including proliferation, differentiation, transformation, and apoptosis. ${ }^{10,11)}$ Mitogenic stimulation rapidly and transiently induces c-Fos expression. The overexpression of c-Fos results in morphological trans- formation of fibroblasts ${ }^{12)}$ and in osteosarcoma formation in transgenic mice. ${ }^{13)}$ The knockdown of c-Fos suppresses the growth of human colon carcinoma cells through a blockade of tumor growth factor (TGF) $\beta 1$ production. ${ }^{14)}$ In addition, c-Fos-deficient mice exhibit severe osteopetrosis because of a lack of osteoclasts. The expression of c-Fos is regulated by multiple pathophysiological stimuli, such as growth factors, chemical stresses, and physical stresses. In general, mitogens activate ternary complex factor (TCF), serum response factor (SRF), and cAMP response element-binding (CREB) protein to promote the transcription of c-Fos gene. ${ }^{15)}$ The activation of SRF via the TCF-dependent pathway involves the Ras-Rafextracellular signal regulated kinase (ERK) cascade. ${ }^{16)}$

It is well-known that the immediate early genes, including c-Fos, are induced in various cultured cells by a brief exposure to serum of serum-deprived cells. ${ }^{17)}$ In the present study, we examined whether cPGES/p23 participates in the serum-induced expression of c-Fos using siRNA technology. The stable knockdown of cPGES in rat fibroblastic 3Y1 cells resulted in a reduction of ERK phosphorylation, which attenuated the induction of c-Fos.

\section{MATERIALS AND METHODS}

Materials The rabbit anti-c-Fos antibody, anti-phosphoERK antibody, anti-ERK antibody, anti-phospho-p38 antibody, anti-p38 antibody, anti-phospho-c-Jun N-terminal kinase (JNK) antibody and anti-JNK antibody were purchased from Cell Signaling Technology (U.S.A.). The mouse anti- $\alpha$-tubulin antibody was from Santa Cruz Biotechnology (U.S.A.). The enzyme immunoassay kit for $\mathrm{PGE}_{2}$ was from Cayman Chemicals (U.S.A.). Indomethacin, PD98059 and SB203580 were from Wako Pure Chemical Industries, Ltd. (Osaka, Japan).

RT-PCR Total RNA was isolated from cells and tissues using TRIzol (Invitrogen, U.S.A.). Synthesis of cDNA was performed with $0.5 \mu \mathrm{g}$ of the total RNA and SuperScript III RT according to the manufacturer's instructions (Invitrogen). Subsequent amplifications of the partial cDNA fragments were performed using $1 \mu \mathrm{L}$ of the reverse-transcribed mixture 


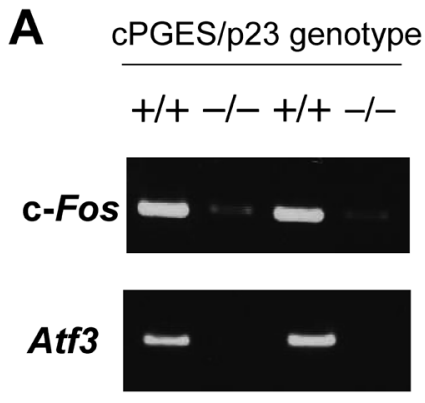

B

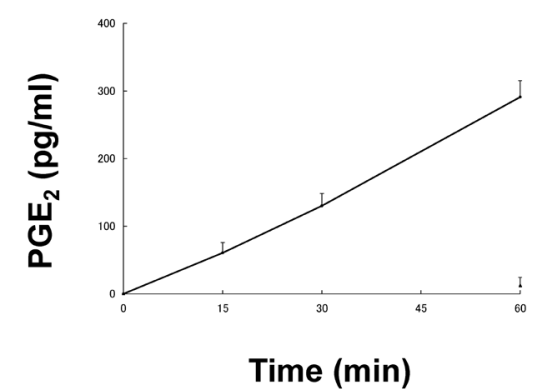

C

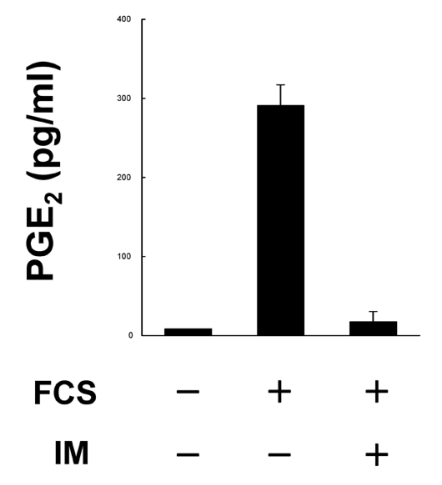

D

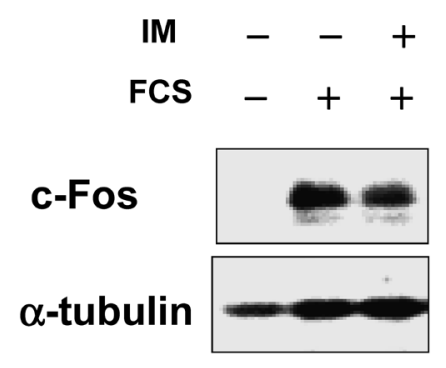

Fig. 1. c-Fos Expression in cPGES/p23-Null Mice and Effects of Indomethacin on c-Fos Expression in 3Y1 Cells

(A) Reduction of c-Fos and Atf3 expression in embryonic lung of cPGES/p23-null mice. Expression of c-Fos and Atf3 mRNA in E18.5 embryonic lung of wild-type or cPGES/p23 knockout mice was examined by RT-PCR analysis. (B) Time course of PGE released from rat fibroblastic 3 Y1 cells in response to $10 \%$ FCS. (C, D) 3 Y1 cells were pretreated with $1 \mu \mathrm{g} / \mathrm{mL}$ indomethacin (IM) for $60 \mathrm{~min}$, followed by $10 \%$ FCS treatment for 60 min and the culture media were taken for PGE 2 enzyme immunoassay (C) and the cell lysates were analyzed by immunoblot with anti-c-Fos antibody (D).

as a template with a set of specific oligonucleotide primers (Sigma, U.S.A.) as follows: (i) mouse/rat c-Fos, sense 5'-CTC CAA GCGGAGACA GATCA-3' and antisense 5'-GCCTAG ATGATGCCGGAAAC-3'; and (ii) mouse Atf3 (activating transcription factor 3), sense 5'-CTGAGA TTC GCC ATCCAG AA-3' and antisense 5'-ACACTC TCC AGT TTC TCT GAC-3'. The PCR mixtures were subjected to 30 cycles of amplification by denaturation $\left(30 \mathrm{~s}\right.$ at $\left.95^{\circ} \mathrm{C}\right)$, annealing $\left(30 \mathrm{~s}\right.$ at $\left.57^{\circ} \mathrm{C}\right)$ and elongation $\left(30 \mathrm{~s}\right.$ at $\left.72^{\circ} \mathrm{C}\right)$. The PCR products were analysed by $1.5 \%(\mathrm{w} / \mathrm{v})$ agarose gel electrophoresis with ethidium bromide.

Quantitative RT-PCR Single-stranded cDNA was generated using $1 \mu \mathrm{g}$ of total RNA as a template and avian myeloblastosis virus RT, using a high capacity reverse transcriptase kit (Applied Biosystems, U.S.A.). Real-time PCR was carried out using the SYBR Green PCR Master Mix (Applied Biosystems) and StepOne (Applied Biosystems) according to the manufacturer's instructions. The PCR primer sets used were: rat c-Fos sense 5'-CCCCTCGCCGAGCTT T-3' and antisense 5'-GCGTTGAAACCCGAGAACAT-3'. The expression level of $\mathrm{c}-\mathrm{FOS}$ was normalized with that of rat glyceraldehyde-3-phosphate dehydrogenase (GAPDH) with a primer set of 5'-CCT GGA GAA ACC TGCCAA GTA T-3' and 5'-CTCGGCCGCCTGCTT-3'. Results represent an average of several independent experiments.

Activation of 3Y1 Cells Rat fibroblastic 3Y1 cells were cultured in Dulbecco's modified Eagle's medium (DMEM) (Nissui Pharmaceutical Co., Tokyo, Japan) containing 10\% fetal calf serum (FCS), as described previously. ${ }^{18)} 3 \mathrm{Y} 1$ cells $\left(3 \times 10^{4} / \mathrm{mL}\right)$ were seeded into $60 \mathrm{~mm}$ tissue culture dishes in
$4 \mathrm{~mL}$ of DMEM containing 10\% FCS and cultured for $2 \mathrm{~d}$. The culture media were replaced with DMEM containing 0.5\% FCS and after culture for $24 \mathrm{~h}, 10 \%$ FCS-DMEM was added to the cultures to assess c-Fos expression and $\mathrm{PGE}_{2}$ synthesis. The culture supernatants were taken for $\mathrm{PGE}_{2}$ enzyme immunoassay ( $\mathrm{PGE}_{2}$ Enzyme Immunoassay kit-Monoclonal; Cayman Chemical).

Establishment of cPGES-Knockdown Fibroblastic 3Y1 Cells To establish cPGES/p23-knockdown 3Y1 cells, we cotransfected $3 \mathrm{Y} 1$ cells with a pSilencer2.0-U6 siRNA expression vector (Ambion) harboring a cPGES/p23-directed siRNA target sequence [5'-GGGCAA AGC TTA ATT GGC TT-3' (residues 278-297 in the open reading frame)] and a pBKCMV vector (Stratagene) using Lipofectamine 2000 (Invitrogen). After the transfection of these plasmids, 3Y1 cells were cultured in medium containing $0.4 \mathrm{mg} / \mathrm{mL}$ G418 (Invitrogen) to select stable clones. As a mock-transfectant, 3Y1 cells transfected with only a pBKCMV vector were used.

Sodium Dodecyl Sulfate-Polyacrylamide Gel Electrophoresis (SDS-PAGE)/Immunoblotting Cell lysates $(10 \mu \mathrm{g}$ protein/lane) were subjected to SDS-PAGE using $12 \%$ gels under reducing conditions. The separated proteins were electroblotted onto Protran nitrocellulose membranes (Whatman/Schleicher \& Schuell) with a bath-type blotter. After blocking with $5 \%(\mathrm{w} / \mathrm{v})$ skim milk in phosphate-buffered saline containing $0.05 \%$ tween 20 (phosphate buffered saline (PBS)-tween), the membranes were probed with the respective antibodies $(1: 5000$ dilution for cPGES/p23 and $\alpha$-tubulin, and 1:2500 dilution for c-Fos, phospho-ERK, phospho-p38 and phospho-JNK in PBS-tween) for $2 \mathrm{~h}$, followed by incu- 
A
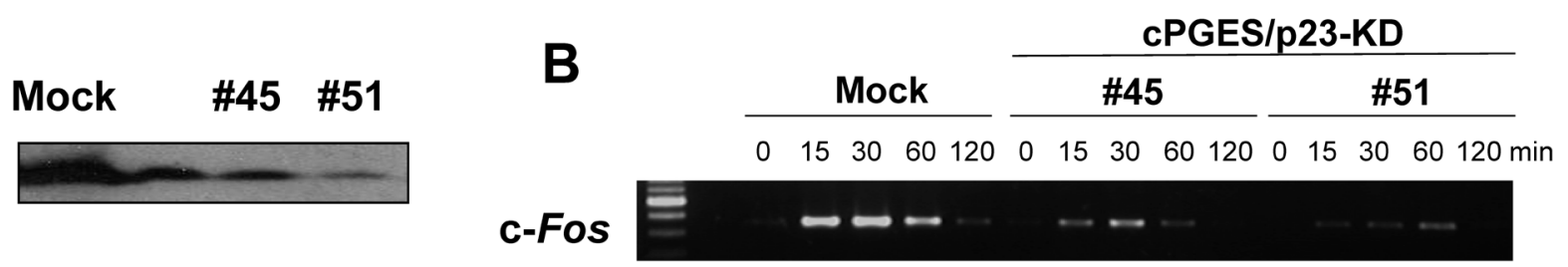

GAPDH $-----\cdots-\cdots-\cdots-\cdots-$

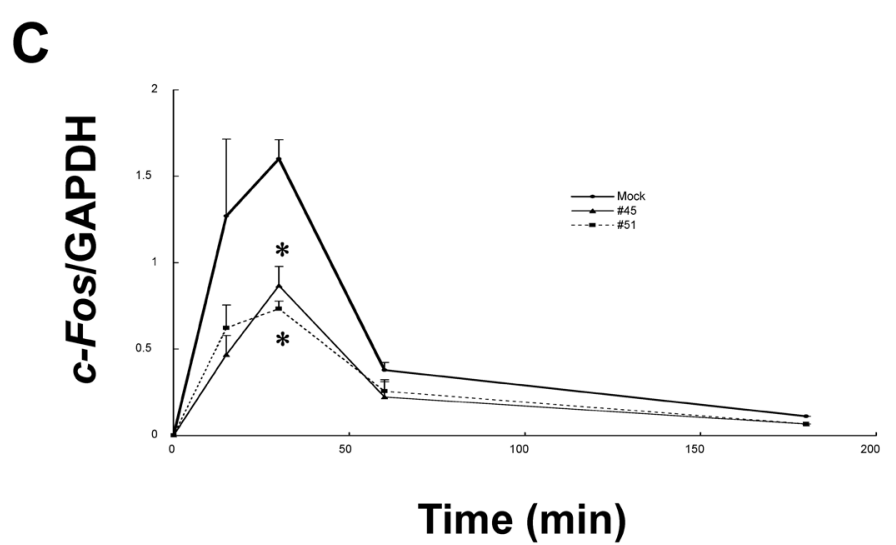

Fig. 2. Serum-Induced c-Fos Expression in cPGES/p23 Knockdown Cells

(A) Protein expression of cPGES/p23 in two independently-isolated cPGES/p23 knockdown (cPGES/p23-KD) cells (referred to as \#45 and \#51) was assessed by Western blotting analysis. (B) Reduction of serum-elicited c-Fos mRNA induction in cPGES/p23 knockdown cells. Expression of c-Fos and GAPDH mRNA in mock-transfected cells (Mock) and cPGES/p23 knockdown cells (\#45 and \#51) was examined by RT-PCR analysis. (C) Time course of c-Fos mRNA expression in serum-stimulated mocktransfected cells (Mock) and cPGES/p23 knockdown cells (\#45 and \#51) was examined by quantitative RT-PCR analysis. Results represent the means \pm standard error. ${ }^{*} p<0.05$ indicates a significant reduction in serum-induced gene expression in the cPGES/p23 knockdown cells compared with that in the mock-transfected cells.

bation with horseradish peroxidase-conjugated anti-rabbit or anti-mouse immunoglobulin $\mathrm{G}(\mathrm{IgG})(1: 5000$ dilution in PBS-tween) for $1 \mathrm{~h}$, and were visualized with the Western Lighting Chemiluminescence Reagent Plus (PerkinElmer, Life Sciences, U.S.A.).

\section{RESULTS}

Expression of Immediate Early Genes Is Decreased in cPGES/p23-Null Mice To search for genes with altered expression in cPGES/p23-null mice, we probed a cDNA array with mRNA isolated from the lungs of cPGES/p23-null and wild-type fetuses. Microarray analyses revealed that the expression of several immediate early genes was significantly decreased in cPGES/p23-null mice compared with that in their wild-type littermates. We selected the two most downregulated genes, c-Fos and activating transcription factor 3 (Atf3) from the list of genes exhibiting decreased expression and then validated their expression levels by RT-PCR. RT-PCR analyses confirmed that cPGES/p23 deficiency led to decreases in transcripts of c-Fos and Atf3 genes (Fig. 1A). Subsequent study focused on the role of $\mathrm{cPGES} / \mathrm{p} 23$ in serum-induced c-Fos expression in rat fibroblastic $3 \mathrm{Y} 1$ cells.

Involvement of $\mathrm{PGE}_{2}$ in Serum-Induced c-Fos Expression in 3Y1 Cells We previously reported that 3Y1 cells produce and release $\mathrm{PGE}_{2}$ in response to various stimuli, such as bradykinin, vasopressin and interleukin (IL)-1 $\beta$, and so we determined the extracellular concentrations of $\mathrm{PGE}_{2}$ after the treatment of $3 \mathrm{Y} 1$ cells with serum. The treatment of $3 \mathrm{Y} 1$ cells with $10 \%$ serum elicited immediate $\mathrm{PGE}_{2}$ synthesis, which rose during $60 \mathrm{~min}$ after stimulation (Fig. 1B). Indomethacin, a COX inhibitor, markedly suppressed $\mathrm{PGE}_{2}$ synthesis in $3 \mathrm{Y} 1$ cells (Fig. 1C). However, the addition of indomethacin only slightly attenuated serum-induced c-Fos protein expression (Fig. 1D). These results suggest that $\mathrm{PGE}_{2}$ synthesized by cPGES/p23 subtly affect c-Fos expression. Thus, we assume that $\mathrm{cPGES} / \mathrm{p} 23$ may influence signal transduction pathway after exposure to the serum.

c-Fos Induction in cPGES/p23 Knockdown Cells To confirm the generality of correlative expression between cPGES/p23 and c-Fos, we established several stable rat 3Y1 fibroblast transformants harboring siRNA targeting cPGES/p23 (Fig. 2A). After choosing two independent clones (referred to as \#45 and \#51) that decreased in cPGES/p23 protein expression levels compared with mock-transfected cells, we assessed their c-Fos mRNA expression levels by RT-PCR and quantitative RT-PCR (Fig. 2B). In mock-transfected cells, c-Fos transcripts were peaked $30 \mathrm{~min}$ after serum treatment and then returned to baseline levels by $120-180 \mathrm{~min}$. In contrast, RT-PCR and quantitative RT-PCR demonstrated that c-Fos mRNA induction in cPGES/p23 knockdown cells was significantly decreased. These results suggest that cPGES/p23 is generally involved in c-Fos expression in vivo and in vitro.

ERK Is Mainly Involved in Serum-Induced c-Fos Expression It is known that SRF is an important regulator of serum-induced gene transcription and that the binding of TCF to SRF is required for activation of the SRF. Several mitogenactivated protein (MAP) kinase pathways have been found to 
A

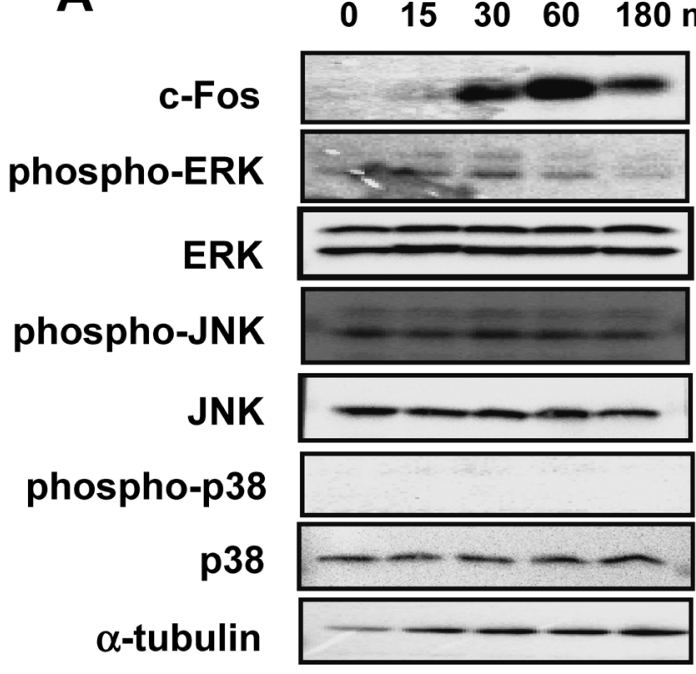

B

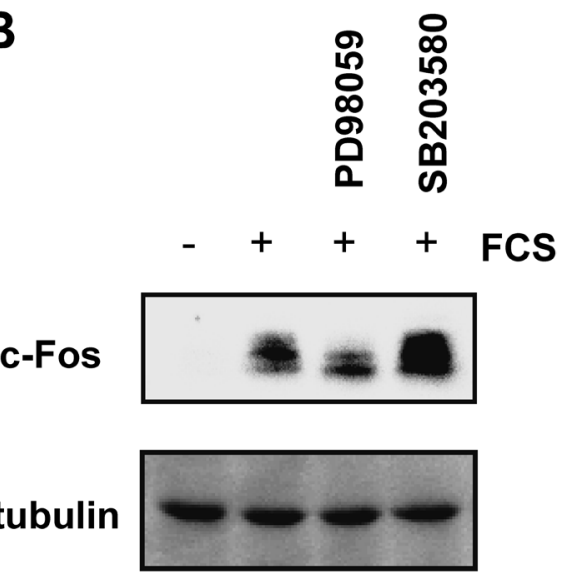

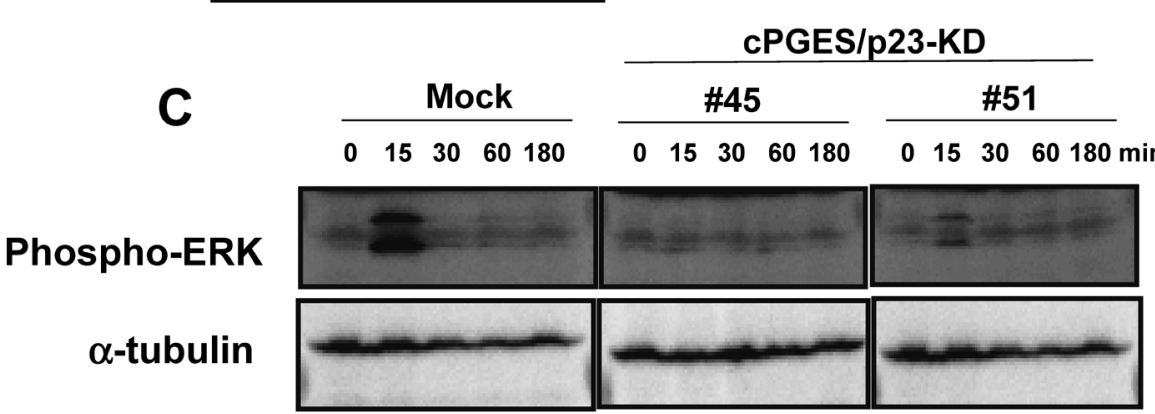

CPGES/P23-KD

Fig. 3. ERK Is Mainly Involved in Serum-Induced c-Fos Expression

(A) 3 Y 1 cells were treated with $10 \%$ FCS for the indicated periods and analyzed by immunoblot with the indicated antibodies. (B) 3 Y1 cells were pretreated with PD98059 or SB203580 for $60 \mathrm{~min}$, followed by $10 \%$ FCS treatment for $60 \mathrm{~min}$ and analyzed by immunoblot with anti-c-Fos antibody. (C) Mock-transfected and cPGES/p23 knockdown 3 Y1 cells were treated with $10 \%$ FCS for the indicated periods and analyzed by immunoblot with anti-phospho-ERK antibody.

activate TCF. Among them, serum stimulation can activate ERK to phosphorylate TCF via the Ras-Raf-MEK1/MEK2 pathway. Thus, we examined the activation of MAP kinases in rat fibroblastic $3 Y 1$ cells after serum stimulation. As seen in Fig. 3A, only ERK showed serum-dependent transient phosphorylation, whereas neither JNK nor p38 did. In addition, ERK phosphorylation preceded the induction of c-Fos protein. PD98059, a selective MEK inhibitor, significantly suppressed serum-induced c-Fos protein expression, whereas SB203580, a selective p38 inhibitor, did not exhibit an inhibitory effect. These results indicate that serum-triggered c-Fos induction is mainly regulated via the ERK pathway in 3Y1 cells (Fig. 3B).

Unexpectedly, serum-elicited ERK activation was significantly attenuated in cPGES/p23 knockdown 3Y1 cells (Fig. 3C), but cPGES/p23 knockdown affected neither JNK nor p38 activation (data not shown). These results suggest that cPGES/p23 may be involved in the pathway of ERK activation, leading to a decrease in c-Fos induction.

\section{DISCUSSION}

cPGES/p23 was first discovered in the progesterone receptor complex. ${ }^{19)}$ It is now known that cPGES/p23 is present in various Hsp90 chaperone complexes containing glucocorticoid receptor and telomerase. ${ }^{20,21)}$ We have previously shown that cPGES/p23-derived PGE $_{2}$ is involved in the normal development of mouse embryonic lungs, and that it has an essential role in the survival of neonates. To date, many papers have described the phenotypes of knockout mice which are deficient in enzymes involved in $\mathrm{PGE}_{2}$ biosynthesis and metabolism (cytosolic PLA $2, \alpha$ COX-1, COX-2, and microsomal PGES-1) or receptors for $\mathrm{PGE}_{2}$ (EP1-EP4). Among them, COX-1/COX-2 double knockout mice and knockout mice lacking the EP4 receptor, a member of the $\mathrm{PGE}_{2}$ receptor family, also exhibited the same phenotype. This is suggesting that $\mathrm{PGE}_{2}$ is needed to close or dilate the ductus arteriosus of neonates during the postnatal period. ${ }^{22,23)}$

On the other hand, cPGES/p23 acts as a transcriptional modulator that not only accelerates glucocorticoid receptor signaling but also attenuates the responses of hormone-bound intracellular receptors by disassembling their transcriptional regulatory complexes. ${ }^{24)} \mathrm{A}$ recent study revealed that cPGES/p23 is involved in the stability of the aryl hydrocarbon receptor (AhR) ${ }^{25)}$ Echtenkamp et al. reported that cPGES/p23 contributes to broad cellular pathways, including Golgi function, ribosome biogenesis, and cell mobility. ${ }^{26)}$ Our present study indicates that cPGES/p23 is, at least in part, involved in the serum-elicited induction of c-Fos. SRF is mainly involved in c-Fos induction, and its activation is carried out through the Ras-Raf-MEK-ERK pathway. Because the knockdown of cPGES/p23 caused a decrease in ERK activation, cPGES/p23 may affect a regulator upstream of ERK. ATF3, another immediate early gene, is also downregulated in cPGES/p23-null mice, and it is known that ERK MAP kinase regulates ATF3 
expression, implying the existence of a cPGES/p23-dependent ERK activation pathway. As mentioned above, cPGES/p23 has multiple cellular functions. Our observation that indomethacin slightly suppressed serum-elicited c-Fos induction indicates that $\mathrm{PGE}_{2}$ released from $3 \mathrm{Y} 1$ cells is not necessary for c-Fos induction. In conclusion, our current study suggests that $\mathrm{cPGES} / \mathrm{p} 23$ is involved in the transient induction of c-Fos rather by serving as a co-chaperone molecule than by supplying the lipid mediator $\mathrm{PGE}_{2}$.

Interestingly, a recent study demonstrated that a natural product known as gedunin, which has been isolated from plants, can bind directly to cPGES/p23. This binding inactivates the chaperoning activities of $\mathrm{cPGES} / \mathrm{p} 23$ and leads to cancer cell death by apoptosis. ${ }^{27)}$ It is obvious that not only Hsp90 but also its co-chaperone cPGES/p23 is becoming promising targets for cancer treatment. Thus, our study on the involvement of cPGES/p23 in c-Fos induction may provide a new aspect of intracellular cPGES/p23 function necessary for cell survival.

Acknowledgments This work was supported by Grantsin-Aid for Scientific Research and "High-Tech Research Center" Project for Private Universities from the Ministry of Education, Culture, Sports, Science and Technology of Japan.

Conflict of Interest The authors declare no conflict of interest.

\section{REFERENCES}

1) Kudo I, Murakami M. Phospholipase $\mathrm{A}_{2}$ enzymes. Prostaglandins Other Lipid Mediat., 68-69, 3-58 (2002).

2) Smith WL, DeWitt DL, Garavito RM. Cyclooxygenases: structural, cellular, and molecular biology. Annu. Rev. Biochem., 69, 145-182 (2000).

3) Kudo I, Murakami M. Prostaglandin E synthase, a terminal enzyme for prostaglandin $\mathrm{E}_{2}$ biosynthesis. J. Biochem. Mol. Biol., 38, 633-638 (2005).

4) Tanioka T, Nakatani Y, Semmyo N, Murakami M, Kudo I. Molecular identification of cytosolic prostaglandin $\mathrm{E}_{2}$ synthase that is functionally coupled with cyclooxygenase-1 in immediate prostaglandin $\mathrm{E}_{2}$ biosynthesis. J. Biol. Chem., 275, 32775-32782 (2000).

5) Johnson J, Corbisier R, Stensgard B, Toft D. The involvement of p23, hsp90, and immunophilins in the assembly of progesterone receptor complex. J. Steroid Biochem. Mol. Biol., 56, 31-37 (1996).

6) Tanioka T, Nakatani Y, Kobayashi T, Tsujimoto M, Oh-ishi S, Murakami M, Kudo I. Regulation of cytosolic prostaglandin $\mathrm{E}_{2}$ synthase by $90-\mathrm{kDa}$ heat shock protein. Biochem. Biophys. Res. Commun., 303, 1018-1023 (2003).

7) Kobayashi T, Nakatani Y, Tanioka T, Tsujimoto M, Nakajo S, Nakaya K, Murakami M, Kudo I. Regulation of cytosolic prostaglandin E synthase by phosphorylation. Biochem. J., 381, 59-69 (2004).

8) Nakatani Y, Hokonohara Y, Kakuta S, Sudo K, Iwakura Y, Kudo I. Knockout mice lacking cPGES/p23, a constitutively expressed $\mathrm{PGE}_{2}$ synthetic enzyme, are peri-natally lethal. Biochem. Biophys. Res. Commun., 362, 387-392 (2007).

9) Nakatani Y, Hokonohara Y, Tajima Y, Kudo I, Hara S. Involvement of the constitutive prostaglandin E synthase cPGES/p23 in expression of an initial prostaglandin $\mathrm{E}_{2}$ inactivating enzyme, 15-PGDH. Prostaglandins Other Lipid Mediat., 94, 112-117 (2011).

10) Shaulian E, Karin M. AP-1 as a regulator of cell life and death. Nat. Cell Biol., 4, E131-E136 (2002).
11) Eferl R, Wagner EF. AP-1: a double-edged sword in tumorigenesis. Nat. Rev. Cancer, 3, 859-868 (2003).

12) Miller AD, Curran T, Verma IM. c-Fos protein can induce cellular transformation: a novel mechanism of activation of a cellular oncogene. Cell, 36, 51-60 (1984).

13) Rüther U, Komitowski D, Schubert FR, Wagner EF. c-Fos expression induces bone tumors in transgenic mice. Oncogene, 4, 861-865 (1989).

14) Pandey MK, Liu G, Cooper TK, Mulder KM. Knockdown of c-Fos suppresses the growth of human colon carcinoma cells in athymic mice. Int. J. Cancer, 130, 213-222 (2012).

15) Hazzalin CA, Mahadevan LC. MAPK-regulated transcription: a continuously variable gene switch? Nat. Rev. Mol. Cell Biol., 3, 30-40 (2002)

16) Johansen FE, Prywes R. Two pathways for serum regulation of the c-fos serum response element require specific sequence elements and a minimal domain of serum response factor. Mol. Cell. Biol. 14, 5920-5928 (1994).

17) Lee S-M, Vasishtha M, Prywes R. Activation and repression of cellular immediate early genes by serum response factor cofactors. $J$. Biol. Chem., 285, 22036-22049 (2010).

18) Kuwata H, Nakatani Y, Murakami M, Kudo I. Cytosolic phospholipase $A_{2}$ is required for cytokine-induced expression of type IIA secretory phospholipase $\mathrm{A}_{2}$ that mediates optimal cyclooxygenase2-dependent delayed prostaglandin $\mathrm{E}_{2}$ generation in rat 3Y1 fibroblasts. J. Biol. Chem., 273, 1733-1740 (1998).

19) Smith DF, Faber LE, Toft DO. Purification of unactivated progesterone receptor and identification of novel receptor-associated proteins. J. Biol. Chem., 265, 3996-4003 (1990).

20) Hutchison KA, Stancato LF, Owens-Grillo JK, Johnson JL, Krishna P, Toft DO, Pratt WB. The 23-kDa acidic protein in reticulocyte lysate is the weakly bound component of the hsp foldosome that is required for assembly of the glucocorticoid receptor into a functional heterocomplex with hsp90. J. Biol. Chem., 270, 18841-18847 (1995).

21) Holt SE, Aisner DL, Baur J, Tesmer VM, Dy M, Ouellette M, Trager JB, Morin GB, Toft DO, Shay JW, Wright WE, White MA. Functional requirement of $\mathrm{p} 23$ and Hsp90 in telomerase complexes. Genes Dev., 13, 817-826 (1999).

22) Loftin CD, Trivedi DB, Tiano HF, Clark JA, Lee CA, Epstein JA, Morham SG, Breyer MD, Nguyen M, Hawkins BM, Goulet JL, Smithies O, Koller BH, Langenbach R. Failure of ductus arteriosus closure and remodeling in neonatal mice deficient in cyclooxygenase-1 and cyclooxygenase-2. Proc. Natl. Acad. Sci. U.S.A., 98, 1059-1064 (2001)

23) Segi E, Sugimoto Y, Yamasaki A, Aze Y, Oida H, Nishimura T, Murata T, Matsuoka T, Ushikubi F, Hirose M, Tanaka T, Yoshida N, Narumiya S, Ichikawa A. Patent ductus arteriosus and neonatal death in prostaglandin receptor EP4-deficient mice. Biochem. Biophys. Res. Commun., 246, 7-12 (1998).

24) Freeman BC, Yamamoto KR. Disassembly of transcriptional regulatory complexes by molecular chaperones. Science, 296, 2232-2235 (2002).

25) Nguyen PM, Wang D, Wang Y, Li Y, Uchizono JA, Chan WK. p23 co-chaperone protects the aryl hydrocarbon receptor from degradation in mouse and human cell lines. Biochem. Pharmacol., 84, $838-850$ (2012).

26) Echtenkamp FJ, Zelin E, Oxelmark E, Woo JI, Andrews BJ, Garabedian M, Freeman BC. Global functional map of the p23 molecular chaperone reveals an extensive cellular network. Mol. Cell, 43, 229-241 (2011).

27) Patwardhan CA, Fauq A, Peterson LB, Miller C, Blagg BSJ, Chadli A. Gedunin inactivates the co-chaperone $\mathrm{p} 23$ protein causing cancer cell death by apoptosis. J. Biol. Chem., 288, 7313-7325 (2013). 